\title{
Talk That Counts: Participation in Practicums and Student Success in Civil Engineering
}

\author{
Z. Simpson*, J. Bester** \\ * Faculty of Engineering and the Built Environment, University of Johannesburg, South Africa \\ ** Department of Civil Engineering Science, University of Johannesburg, South Africa
}

\begin{abstract}
Engineering courses across the globe include practical components generally undertaken in small groups. This study aims to determine whether the quantity and quality of students' participation in these group-based practicums could be correlated with their academic performance. A first year course in Concrete Technology was selected, and groups of students were filmed as they undertook a practicum that required them to mix, test, cast and crush concrete cubes as per the guidelines of two established procedures. Approximately four hours of film was then time-coded according to student activity. The resulting transcripts were analysed quantitatively in terms of total time spent on specific activities, and qualitatively in terms of the nature of student engagement with those activities. The results show that group discussion may have a greater impact on student learning than time spent on the task itself. However, this depends on the specific nature of this talk. Implications of the study include the fact that attention needs to be given to designing group tasks in such a way that they facilitate group interaction, and the fact that tutors and lecturers should promote group discussion and be aware of interactional dynamics that act to the detriment of student learning.
\end{abstract}

Keywords: Practicums; student success; engineering education

\section{Introduction}

"Science educators readily agree that laboratory learning should include hands-on activities, student-centered learning, problem identification and solving, and collaboration" (Lerner, 2007, p. 192). However, the learning achieved through such measures often fails to meet educators' expectations. It is by no means a given that students will be able to apply what they have learnt in practicums: in fact, groups are often dysfunctional in their collaboration with each other. The civil engineering curriculum at the research site studied herein includes a number of courses that include laboratory, or practical, components. In these practicums, students are required to perform, in groups, experimental laboratory work before writing about their activities in the form of a laboratory report. The purpose of this is to replicate, in as authentic a manner as possible, the practices of professionals in industry (Lerner, 2007). This study aims to determine whether relationships can be drawn between students' participation in these practicums and their performance, both in subsequent laboratory reports (that should reflect their mastery of underlying theory) and in the course as a whole.

The course chosen was called Concrete Technology, which aims to equip students with knowledge and skills relevant to successful casting, testing and maintenance of structural concrete. This course forms part of the first year of a four-year degree in civil engineering, and included a strong practical component. During the semesterlong course, the main practicum required students to cast concrete cubes as per the guidelines of two established procedures for doing so. The one procedure, the eyeball method, requires the concrete technologist or engineer to use a high degree of judgement in attaining the desired concrete mix. Such judgement requires experience, and experienced concrete technologists are able to make sophisticated judgements about the nature of concrete through mere visual inspection. The second method, the Cement and Concrete Institute method, is far more rigid in its delineation of exact 
quantities of cement, stone, sand and additives. In the practicum under study herein, students were required to mix sufficient concrete to cast three cubes of each mix. Once cast, the cubes were placed in a curing bath for seven days, after which the cubes were crushed so as to determine their compressive strength.

The remainder of this paper begins with a more detailed description of the methods deployed in the study. Thereafter, the results are presented and discussed before final conclusions and recommendations are drawn.

\section{Methods}

The concrete mix design practicum was undertaken over a series of Friday afternoons. Each week, groups were asked to volunteer to participate in this study and the first group to agree was given further information about the project and asked to give informed consent to be filmed; included herein was a guarantee of the anonymity of the research participants (Cohen et al., 2007 provides a useful overview of research methods in educational settings). Filming was selected as it facilitated more reliable observation (Swann, 1994), as it would have been difficult to generate useful field notes given the pace of activity of the students. In total, two groups of students were filmed as they mixed, tested and cast their two batches of concrete. Each group consisted of four members. The groups broadly reflected the demographics of the classroom and the overall student body. A sample of 8 students is relatively small, but this was done intentionally as the subsequent analytical approach was highly detailed, in that both the quantity and quality of students' engagement in the practicum was examined.

The casting practicum took between one and two hours per group. A week later, the same group was filmed as they crushed the cubes, using a crushing machine, and obtained the seven-day compressive strength of the cubes. This process took approximately 30 minutes per group. In total, around four hours of footage was obtained. All footage was time-coded, a process which was aggregated per individual group member. That is to say, the activities of each group member were separately time-coded. This allowed for analysis of individuals' time spent on various activities. Activities were grouped into four categories: physical engagement with the concrete, discussion with colleagues, doing nothing, and a generalised other category. The other category included items such as asking the lecturer questions, collecting tools and equipment and so on. Time spent on each category of activity was summed for correlation with the students' academic performance, measured by way of their results achieved in the subsequent practical report, and in their overall performance in the course. This constituted the quantitative component of the analysis.

The selected students also gave permission for copies of their practical reports to be made available to the researchers. Within each broad category used for the quantitative analysis, fine-grained qualitative analysis was undertaken of the nature of the students' engagement in the practicum. This engagement was correlated with their actual reports. That is to say, at the point at which specific calculations were undertaken, for example, analysis of the nature of the engagement, as seen in the film data, and the product of that engagement, as seen in the practical report produced, was performed. 


\section{Results and Discussion}

\section{Physical Engagement with Concrete Casting Process}

As part of the practicum, participants were required to measure out quantities of sand, cement, stone, water and additives, mix these together, perform a slump test (which measures the consistency of the concrete), and pour the concrete into cubes. The amount of time each student spent engaging physically with the process of casting concrete was tracked quantitatively, and correlated with the students' performance in the lab report and in the course as a whole. The results of the study indicate that there was no correlation evident between the amount of time individual students spent directly working with the concrete, and their performance (see Figure 1).

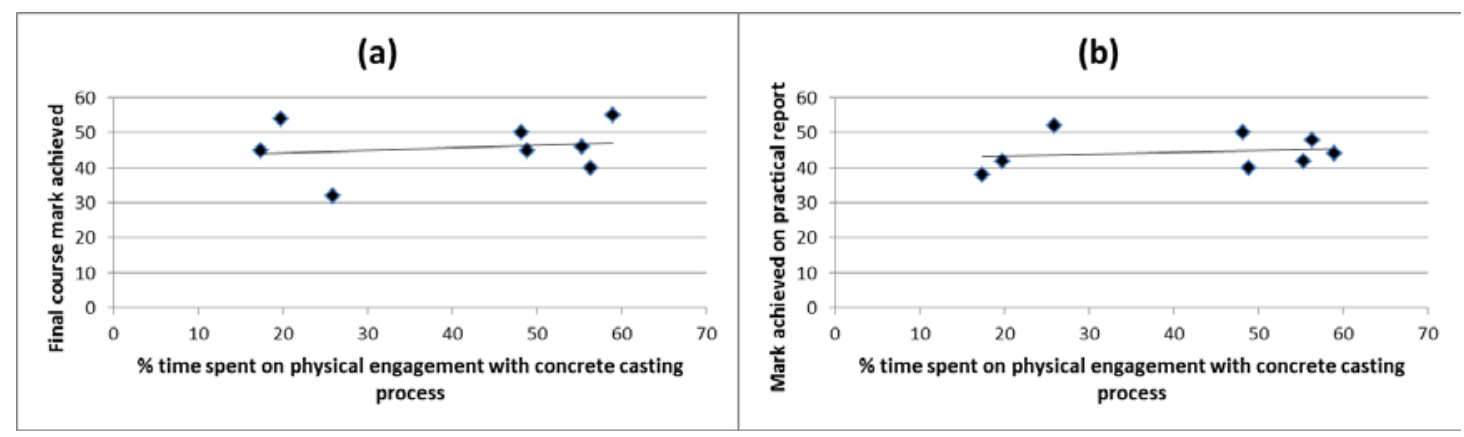

Figure 1. Correlation of percentage time spent on physical engagement with the concrete casting process with (a) performance in the course as a whole, and (b) performance in report submission.

Although no correlation in this regard was evident, it is worth noting that there is a divide between the (largely) theoretical impetus of tests and exams in higher education, and the more practical basis for practitioner knowledge. As such, although direct physical engagement with the concrete did not benefit students in subsequent report writing, tests and exams, the experience of doing so may well benefit them as potential future concrete technologists. This is because expertise as a concrete technologist resides in practitioners' ability to read concrete: that is, to make deductions about its properties and visually inspect it to determine its suitability for use in construction. This notion of reading concrete is taken from Wang and Heath (2011 - see also Scollon and Scollon, 2009), who argue that aspects of the built environment carry complex and diverse signs that are meaningful to the expert viewer. Such expertise requires extensive experience and direct physical engagement in the concrete casting process.

\section{Talk that Counts}

The quantitative analysis revealed that there was some degree of correlation between the amount of time participants spent in discussion with one another and their academic performance (see Figure 2). This correlation was weak at best, and did not apply to their performance in the report. This may be because the written report introduced issue around report writing ability, which influenced their overall performance. However, in both groups, it was evident that the students that spent the most time engaging their fellow group members in discussion, performed better in the course (though not in the practical report submitted after the practical). In one of the groups, the correlation was direct in that the member who performed best in the 
course, spent the most time in discussion with his peers (and, interestingly, the least time physically engaged with the concrete casting process), the second-best performer spent the second most time in discussion with peers, and so on. In the other group, the correlation was evident, but not as direct (a point returned to in the following section). Nonetheless, in the second group, the member who spent the least time engaging with his peers, performed the worst amongst his group members, ultimately achieving a failing grade.

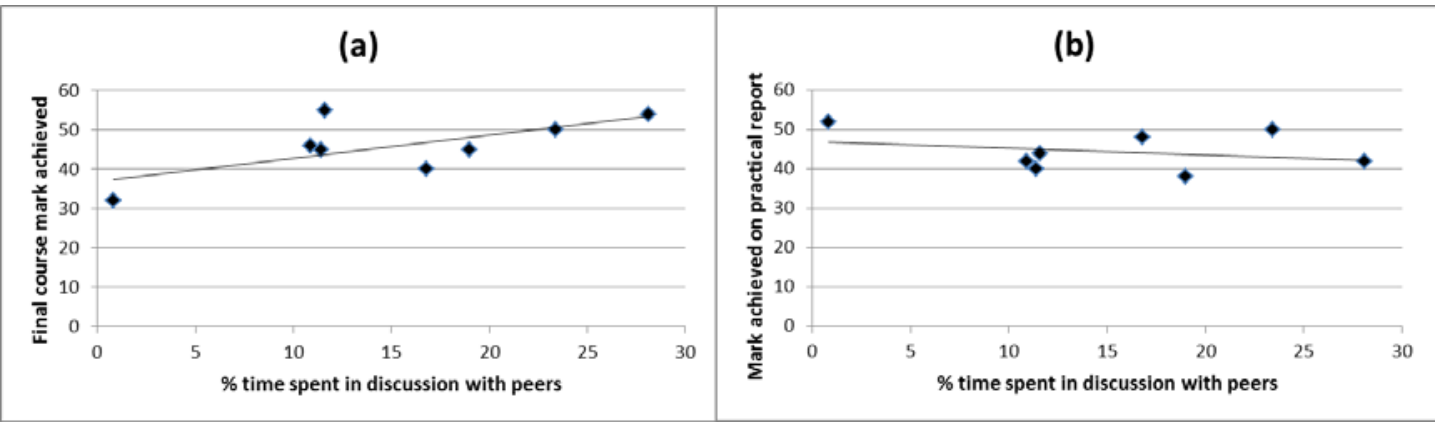

Figure 2. Correlation of percentage time spent on discussion with group peers with (a) performance in the course as a whole, and (b) performance in report submission.

These results suggest that group discussion is an integral learning component within group-based practicums, and may be of greater pedagogic value than direct physical engagement with the object of focus of the practicum. Such discussion with peers appears to foster connections between theory and practice that assist student learning in the mid- to long-term. However, the qualitative analysis revealed that not only is it the case that talk counts more than physical engagement, but that specific kinds of talk count more than others.

\section{The Talk that Counts}

It is unsurprising that a correlation exists between group interaction and academic performance. As Luff et al. (2009) demonstrate, ideas emerge from and are articulated through interaction. However, the correlation between academic performance and discussion with peers was not without anomalies. The focus of subsequent qualitative analysis was on these anomalies. In the discussion that follows, two individual student participants are discussed: they have been given the pseudonyms Thabo and Miriam.

Thabo spent more time than anyone else in his group directly and physically engaged in the concrete casting process. Regarding time spent in discussion with peers, the two top performers in his group spent $28 \%$ and $23 \%$ of their time in discussion respectively. Thabo spent the third most time in discussion with peers: $17 \%$. What was noticeable in this group was the qualitative difference in the type of talk that Thabo had with his peers, and the type of talk that the two top performers had with each other.

Thabo primarily engaged with his peers on matters regarding logistics and practicalities. He would debate with his colleagues as to which equipment to use, how best to achieve certain logistics, and so on. His input in this regard was valued by his fellow group members, who regularly agreed with his suggestions and praised his ideas as good. However, any and all discussion within the group that involved referring back to the course textbook, and to underlying principles, as well as to the calculation tasks required as part of the practicum, was held between the two top 
performers. Thabo never participated in such discussions, and nor did the fourth member of the group. Whereas the top two performers' discussion with each other centred around the use of documents (the textbook and the information sheet provided), Thabo's engagement with his peers primarily centred around equipment and materials. In such contexts, documents such as the textbook and information sheet serve to shape practices as meaningful (Street et al., 2009) and access thereto can thus act as a proxy for access to learning.

It was evident within this group, therefore, that there was a division of labour between the group: where the top performing students were responsible for the intellectual aspects of the practical task, and where Thabo (and, to a lesser extent, the fourth member of the group) was responsible for the practical components. As previously mentioned, in the world of the professional concrete technology practitioner, these practical tasks may be highly valued, but in the academic environment, it is the focus on underlying principle, and on achieving the set academic requirements, for which students are given credit. Assuring good knowledge-sharing routines between students is vital to the success of engineering education (Juhl and Lindegaard, 2013). Furthermore, the ability to find and use knowledge are important for future employability and lifelong learning (Evers et al., 1998), and all students should thus be included in such activities.

In the other group, Miriam spent more time than any of her peers in discussion with group members (19\% of her time was spent on this). However, two of her peers ultimately performed better, despite the fact that they spent only $12 \%$ and $11 \%$ of their time in discussion with group members respectively. The participant who spent $12 \%$ of his time in discussion with peers was the best performing student in the group, by some margin. Again, it was evident that this student was primarily involved in discussion about the task and the underlying expectations and principles. This discussion was largely held with Miriam, and not with the other two members of the group (the one, like Thabo, was consulted largely only on practical matters, and the other generally avoided all discussion and simply did what he was told to do by other group members).

Despite the fact that Miriam was a core participant in the decision-making within the group, she still performed relatively poorly in the module. Upon closer inspection of the data, it became evident that the explanation for this may reside in the nature of her activity when she was neither working directly with the concrete or engaged in discussion with her peers, which accounted for more than $60 \%$ of her time. Whereas other student participants (in both groups) spent this time standing watching their group members, or discussing matters with tutors and lecturers, or fetching, cleaning and returning equipment, Miriam spent this time in discussion with her friends who were in another group nearby. Her involvement in her own group was, therefore, fleeting and characterised by bursts of involvement. She would return to the group, catch up on what had been done, give input into what needed to be done next, and then leave the group to return to her friends. Her attention was thus scattered and, despite the fact that she was relatively strong academically, it could be argued that her lack of focus and continuous engagement, may have been to the detriment of her academic performance.

The benefits of group work, and co-operative learning, include the fact that weaker students can benefit from one-to-one tutoring from stronger team mates and stronger team mates gain a greater depth of understanding that comes from teaching others 
(Bullard and Felder, 2007). However, as Bullard and Felder (2007) further argue, these benefits can only be realised if positive interdependence can be fostered within the group. As such, tutors and lecturers should be cognisant of potential behaviours that work against group interdependence. This may include strategies that reward group collaboration and positive group behaviours, rather than just examining the final product.

\section{Conclusions}

The important of team work and effective communication in engineering education has been well documented (see Sulcas and English, 2010, for an example from the South African literature). This study has presented a small-scale but fine-grained investigation of two groups of first year civil engineering students, as they cast, tested and crushed concrete cubes as part of a concrete technology practicum. It was found that, in this context, the discussion that group members have with their peers may have greater impact on their understanding of principles and practices underpinning their chosen field of study, than their direct physical engagement with the object of focus of the practicum. More importantly, it has demonstrated that the nature of this discussion is of importance: those group members who discussed issues on the basis of the academic requirements and the principles underpinning them fared better than those who focused on the practical issues involved in completion of the task. Indeed, as Evers et al. (1998) argue, the ability to gain knowledge from everyday experiences is an integral component of learning.

The implications of these findings are three-fold. Firstly, it implies that group-based practicums should be designed in such a way that group discussion is a crucial component of the practicum, and the focus should not be placed solely on the completion of the actual experimental work. That is to say, students should be given opportunities to discuss and interrogate what they are doing, as such discussion is integral to the meaningful completion of the task.

Secondly, tutors and lecturers should receive training as to the dynamics of group activity, so that they can become attuned to the nuances of group dynamics and intervene where learning alliances are formed that exclude other group members from the intellectual and decision-making life of the group. Linked to the first point, these tutors and lecturers should be less focused on the completion of the task per se, but on the group interactions and dynamics, which may play a greater role in fostering or hindering learning.

Finally, from a methodological perspective, this paper demonstrates how the combined quantitative and qualitative analysis of film data can be used productively to understand the learning activity of group members, and identify behaviours that may be detrimental to student learning. Such understanding arises from the methodological process of grouping student activities, identifying anomalies and probing these anomalies through in-depth investigation and analysis. 


\section{References}

Bullard, L.G. \& Felder, R.M. (2007). A student-centered approach to teaching material and energy balances: 2. Course delivery and assessment. Chemical Engineering Education, 41(3), 167-176.

Cohen, L., Manion, L. \& Morrison, K. (2007). Research Methods in Education. London: Routledge.

Evers, F. T., Rush, J. C. \& Berdrow, I. (1998). The Bases of Competence: Skills for Lifelong Learning and Employability. San Francisco: Jossey-Bass.

Juhl, J. \& Lindegaard, H. (2013). Representations and visual synthesis in engineering design. Journal of Engineering Education, 102(1), 20-50.

Lerner, N. (2007). Laboratory lessons for writing and science. Written Communication, 24, 191-222.

Luff, P., Heath, C. \& Pitsch, K. (2009). Indefinite precision: Artefacts and interaction in design. In: Jewitt, C. (ed). The Routledge Handbook of Multimodal Analysis. London: Routledge.

Scollon, R. \& Scollon, S. W. (2009). Multimodality and language: A retrospective and prospective view. In: Jewitt, C. (ed). The Routledge Handbook of Multimodal Analysis. London: Routledge.

Street, B., Pahl, K. \& Rowsell, J. (2009). Multimodality and New Literacy Studies. In: Jewitt, C. (ed). The Routledge Handbook of Multimodal Analysis. London: Routledge.

Sulcas, G. \& English, J. (2010). A case for focus on professional communication skills at senior undergraduate level in Engineering and the Built Environment. Southern African Linguistics and Applied Language Studies, 28(3), 219-226.

Swann, J. (1994). Observing and recording talk in educational settings. In: Graddol, D., Maybin, J. \& Stierer, B. (eds). Researching Language and Literacy in Social Context. Clevedon: Multilingual Matters/Open University.

Wang, Q. \& Heath, T. (2011). Towards a universal language of the built environment. Social Semiotics, 21(3), 399-416. 